\title{
COMPARATIVE FRAMEWORK OF CALCIUM PHOSPHATES-BASED PRODUCTS DERIVED FROM SUSTAINABLE MARINE AND TERRESTRIAL RESOURCES FOR BIOMEDICAL APPLICATIONS
}

\author{
AURA-CĂTĂLINA MOCANU ${ }^{a}$, MARIAN MICULESCUa,, \\ ROBERT-CĂTĂLIN CIOCOIU', TUDOR-MIHAI BUTTEa, \\ ANA-IULIA BIȚA ${ }^{a}$, CLAUDIA-GEORGIANA MILEA ${ }^{a}$, \\ AURORA ANTONIAC ${ }^{a}$, MARIUS VASILESCU ${ }^{a}$, OCTAVIAN TRANTE ${ }^{a}$, \\ CIPRIAN POP ${ }^{a}$, LUCIAN-TOMA CIOCAN ${ }^{b}$
}

\begin{abstract}
Processing calcium and phosphor-rich natural resources, such as marble and seashells, and bovine and fish bones, envelops an environmentally friendly and eco-sustainable promising alternative for developing biomimetic products for various orthopaedic applications. In this regard, convenient, efficient, facile and completely reproducible technologies were involved in the fabrication process of biogenic calcium phosphates-based products through the conversion of the proposed resources. The aim of this research was to comparatively evaluate the morpho-compositional, structural and mechanical features of the developed products, subjected in advance to an air sintering program. The results revealed that the high temperature affects differently the morphological characteristics of the samples and facilitates the conservation of several elements, traced from their natural marine or terrestrial habitat. Moreover, the nature of the initial precursors clearly influenced the final composition of the samples: biphasic configuration for calcium carbonate derived products versus single phase for the calcium phosphate ones. The mechanical features are also a composed result of the resources type and sintering process, with significant recorded differences. Therefore, this study unveils the prospect for suitable strategies in terms of adequate natural precursor, fabrication technology and final properties of the biogenic products destined for a certain application in the biomedicine field.
\end{abstract}

Keywords: marble, seashells, bovine bone, fish bone, biogenic hydroxyapatite, compact products, comparative assessment

a University Politehnica of Bucharest, Department of Metallic Materials Science, Physical Metallurgy, 313 Splaiul Independentei, 060042, J Building, District 6, Bucharest, Romania.

b "Carol Davila” University of Medicine and Pharmacy, Prosthetics Technology and Dental Materials Department, 37, Dionisie Lupu Street., District 1, 020022, Bucharest, Romania.

*Corresponding author: marian.miculescu@upb.ro,m_miculescu@yahoo.com 


\section{INTRODUCTION}

The production of daily waste materials by both private and public sectors of the population with defined activities in various industrial fields became an ongoing environmental problem of the current decade. The first negative outcomes were perceived by the end of the last century and awakened a great concern in terms of wastes disposal around the globe [1]. The sensibility towards environmental issues associated with the incremented aging facet of the population, often leading to multiple orthopaedic and dental incidents or reparatory surgeries, led to a continuous inter-connected development oriented for providing high class products and an enhanced healthcare system based on modern and efficient treatments [2-6].

In this light, the challenge arose in the fabrication area of ecocompatible and naturally-based bioproducts which responds to the task in hand by encouraging the exploitation of multiple marine and terrestrial raw resources (otherwise considered as a pollution or a bacterial growth factor) $[7,8]$, the energy saving and the substitution of chemical reagents for providing materials with improved qualities and features [9-11].

The emergence of such materials has been a motivating component for scientists worldwide and underscore the need for expanding the preparation and applicability of calcium phosphates (bulk/ceramic particles, 3D compact/ porous products, injectables or coatings), as targeted osseous treatment solutions used in biomedical applications (orthopaedic, dental or even plastic surgery) [12-18]. Native bones are composite materials made of $\sim 70 \%$ mineral component and $\sim 30 \%$ of organic matter and water [19-22]. Various types of calcium phosphates (CaPs) - hydroxyapatite (HA), $\beta$-tricalcium phosphate $(\beta-T C P)$ or biphasic calcium phosphates $(B C P)$ - are clinically studied and desired due to their close similarity with the mineral bone and teeth component's composition, biocompatibility, bioactivity and biodegradability $[19,20,23-26]$. An advantageous combination of biodegradability and mechanical features (high strength and toughness) is still out for quest, mainly because a high degree of biodegradable component rarely leads to strong mechanical bonds [24, 27-30].

To solve these challenges and to overcome the current flawed solutions for bone restoration (allografts, xenografts, autografts) [31-34], researchers looked for creative responses in the natural environment. Dedicated studies reported considerable knowledge regarding the involvement of marine and terrestrial resources of both calcium carbonate (invertebrates calcified structures: seashells, snails, etc., marble or eggshells) and calcium phosphate (vertebrates' bones: fish bones and mostly bovine bones) [7, 21, 27, 
35-38]. Although seashells, marble or bovine bones were more intensively investigated in the last few years, fish bones have recently attracted real interest. Moreover, the incorporation of various chemical elements from their native habitat (e.g. Mg, Na, Si, F) [19, 39, 40] stands as a particular advantage against conventional commercial materials prepared mostly from synthetic reagents [41].

In terms of processing routes, regardless of the natural precursor and the synthesis method (wet chemical precipitation, sol-gel, hydrothermal procedures or thermal processing) [27, 37, 42, 43], the main focus is oriented towards the optimum variation of the processing parameters for fine-tuned features (morphological, compositional and mechanical). Given that new bone tissue was proved to grow into the pores of the implanted products, it was realized that even compact products comply best in vivo if a porous morphology is assured. Moreover, the pores could also assure a favourable surface for cells adhesion [44] and a better mechanical interlocking of the new grown tissue and positively influence the soluble character oh the synthesized ceramics (also dependent on the HA/ $\beta$-TCP ratio) $[14,45]$.

Consequently, this study aims to expose and correlate the optimum natural resource and fabrication technology for the development of products based on biogenic calcium phosphates (mainly HA and/or $\beta$-TCP). The framework involved marine and terrestrial resources from two types of materials: calcium carbonate (marble and seashells) and calcium phosphate (bovine and fish bone) as initial source of calcium and/or phosphor. The proposed precursors are convenient candidates due to the highly promising researched area in terms of conversion procedures. Also, we advertise for the first time the comparison of prospect four natural precursors and two synthesis technologies. Moreover, the comparative investigation of the developed products features contributes to a significant advance for the adequate selection of bone reconstruction materials.

\section{RESULTS AND DISCUSSION}

\section{Morpho-compositional evaluation}

The morpho-compositional features of sintered products derived from two calcium carbonate resources (marble and seashell) and two calcium phosphates precursors (bovine bone and fish bone) are comparatively presented in Figure 1. 
A.-C. MOCANU, M. MICULESCU, R.-C. CIOCOIU, T.-M. BUTTE, A.-I. BITฺ̆

C.-G. MILEA, A. ANTONIAC, M. VASILESCU, O. TRANTE, C. POP, L.-T. CIOCAN

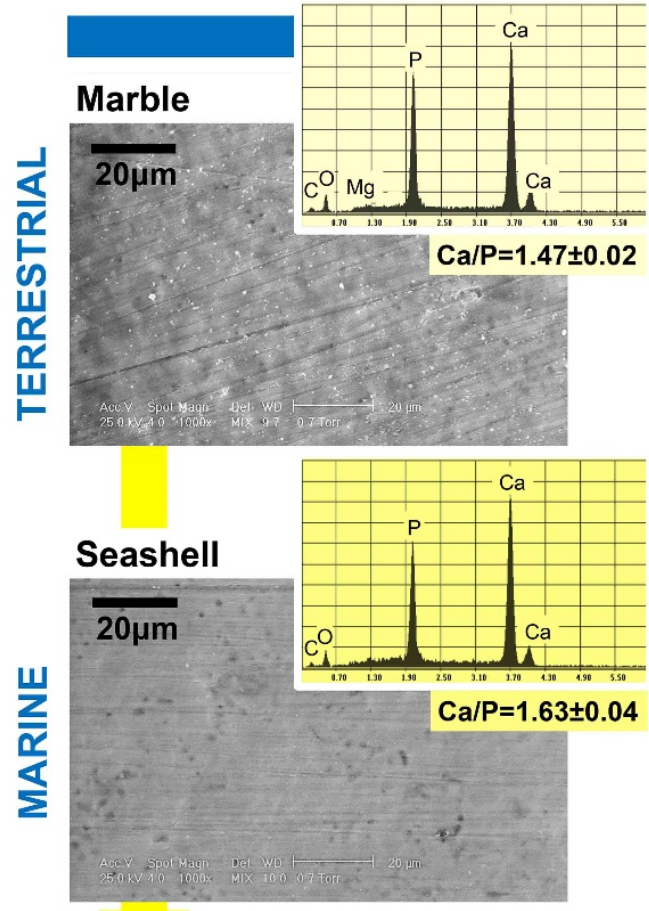

Calcium carbonates

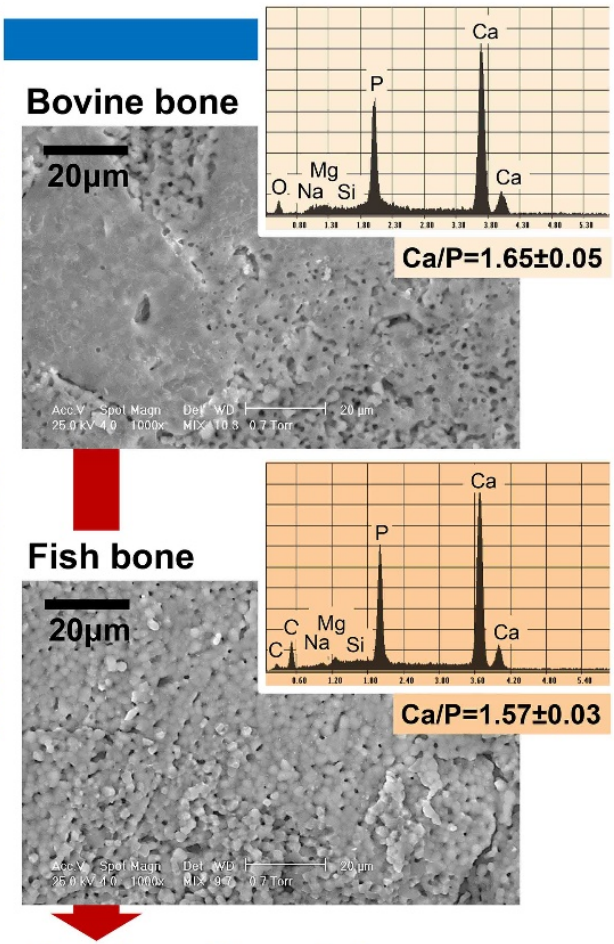

Calcium phosphates

Figure 1. SEM-EDS results for bioceramic sintered products prepared from marble, seashell, bovine bone and fish bone precursors. Variation of $\mathrm{Ca} / \mathrm{P}$ atomic ratio of the final bioceramic products (calculated as a mean of $\mathrm{n}=3$ results \pm standard deviation).

The results depict a clear difference in terms of compactness degree between the two types of products, which can be traced back to the particles shapes and sizes of all bioceramic powders derived from the four precursors. During the calcium carbonates conversion process, the obtained particles envelop a rounded and spherical aspect [36, 37, 42], while the calcium phosphates transformation leads to elongated/polyhedric particles with sharp edges $[21,27]$. In this light, for marble and seashell derived products, the sintering stage led to highly compacted microstructures with few residual micropores unevenly dispersed on the samples surface and with variable sizes and grain shapes difficult to discriminate. In contrast, the sintered bovine bone and fish bone derived products revealed similar morphologies, with significantly induced densification of the bioceramic materials and strongly interconnected particles. However, the porosity and the pore sizes 
and their distribution differ: for the bovine bone derived products, two areas were depicted - a mostly compact and uniform one, surrounded by areas with accentuated porosity and enlarged pore sizes distribution, while for the fish bone derived products, the microporous character is visible on the entire surface, with different distribution of the pore sizes.

The composition of the synthesized bioceramic products included $\mathrm{Ca}$, $\mathrm{P}$ and $\mathrm{O}$ as major elements, specific to calcium phosphates materials, as revealed by the EDS spectra in Figure 1. Based on the natural origin of these products, variable quantities of other elements could be also traced. In the case of marble derived products, Mg was identified due to the dolomitic polymorphic form of the calcium carbonate, and its presence was preserved after chemical and thermal processing of the resource [36, 37]. Besides Mg, peaks of $\mathrm{Na}$ and $\mathrm{Si}$ were also present in the EDS spectra of bovine bone and fish bone derived products [21, 27, 47]. The compositional key indicator for naturally-derived products was the $\mathrm{Ca} / \mathrm{P}$ atomic ratio (inset in Figure 1). The $\mathrm{Ca} / \mathrm{P}$ ratio varied between 1.47 for marble derived samples and 1.65 for bovine bone-derived ones. Values close to the theoretical stoichiometric HA value of 1.67 [21], were found only for the samples derived from bovine bone and seashells [28].

\section{Structural investigations}

\section{1. $X R D$}

The XRD patterns of the sintered products are comparatively displayed in Figure 2. The phase transformation undergone by all samples was anticipated and consistent with our previously published results, demonstrating the reproducibility of both developed conversion technologies for both types of natural resources [21, 27, 28, 35, 36, 46].

The major diffraction maxima corresponding to hexagonal HA (ICDD: 00-009-0432) was identified for all sintered samples, with clear and sharp HA peaks, indicating that materials contain highly crystalline $\mathrm{HA}$ as major phase. The indirect synthesis route and the thermal treatment applied to the marble and seashell derived samples, facilitated the coexistence of HA and $\beta-T C P$ (ICDD: 00-009-0169) in different ratios. This biphasic configuration appears to be specific to this type of materials $[28,36,46]$. For calcium phosphates derived samples, HA was consistently found as the single phase, due to the presence of stabilizing elements (e.g. magnesium) which prevent the decomposition of bovine and fish bones at $1200^{\circ} \mathrm{C}$, and is preserved in the materials' structure [21, 27], as evidenced by the EDS results (Figure 1).

However, for bovine and fish bone derived products, traces of $\mathrm{CaO}$ phase (ICDD: 01-082-1690) were clearly spotted in the diffraction patterns. 
These low limit traces were previously identified for samples prepared through repeated high temperature calcination and sintering processes and could be the result of the dehydroxylation of the material [27].

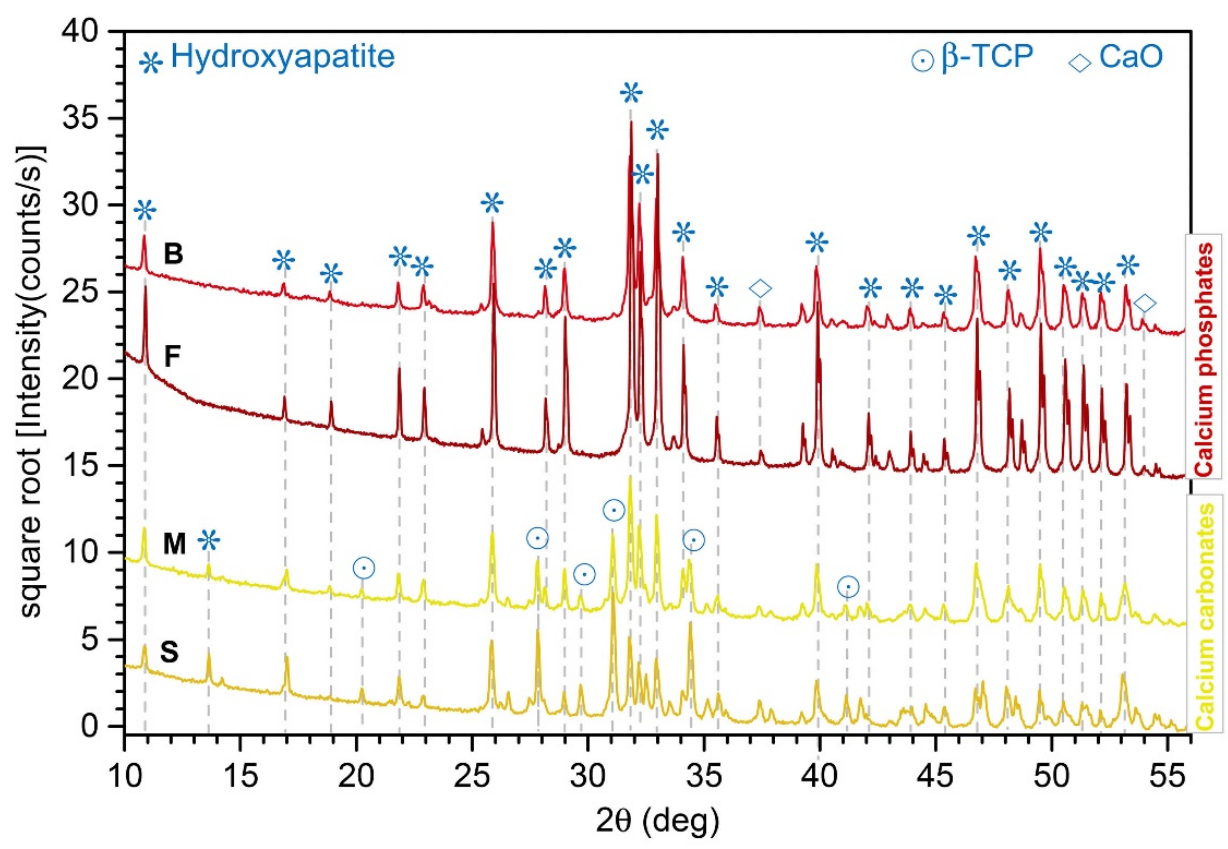

Figure 2. XRD patterns of bioceramic products derived from marble $(M)$, seashell $(S)$, bovine bone $(\mathrm{B})$ and fish bone $(\mathrm{F})$ precursors by chemical synthesis/calcination and sintering at $1200^{\circ} \mathrm{C}$.

\subsection{FTIR-ATR}

The FTIR-ATR spectra of the sintered products are comparatively presented in Figure 3. A zoomed caption of the relevant functional groups in the final region of the spectra is displayed as inset-figure for a clear visualization.

The IR spectra of all investigated samples included bands specific to $\mathrm{HA}$, corresponding to the characteristic vibrations of the orthophosphate functional groups ((PO4) $\left.)^{3-}\right)[48,49]$ : $\mathrm{v}_{4}$ asymmetric bending $(\sim 552, \sim 557$ and $\left.\sim 600 \mathrm{~cm}^{-1}\right), v_{1}$ symmetric stretching $\left(\sim 945, \sim 961\right.$ and $\left.\sim 974 \mathrm{~cm}^{-1}\right)$ and $v_{3}$ asymmetric stretching $\left(\sim 1020\right.$ and $\left.\sim 1089 \mathrm{~cm}^{-1}\right)$. Additional bands were identified, corresponding to structural hydroxyl units [48, 49]: libration of $(\mathrm{OH})^{-}$ groups in HA $\left(\sim 633 \mathrm{~cm}^{-1}\right)$ - more prominent for bovine and fish bone derived products, and stretching of $(\mathrm{OH})^{-}$groups in $\mathrm{HA}\left(\sim 3572\right.$ and $\left.\sim 3640 \mathrm{~cm}^{-1}\right)$. 
These results endorse the XRD findings and are in good agreement with previously reported studies in terms of sintered naturally-derived products, from either calcium carbonate or calcium phosphate resources. One could also notice that the high temperature treatments support the removal of carbonate groups usually present in the raw synthesized materials $[21,37,50]$.

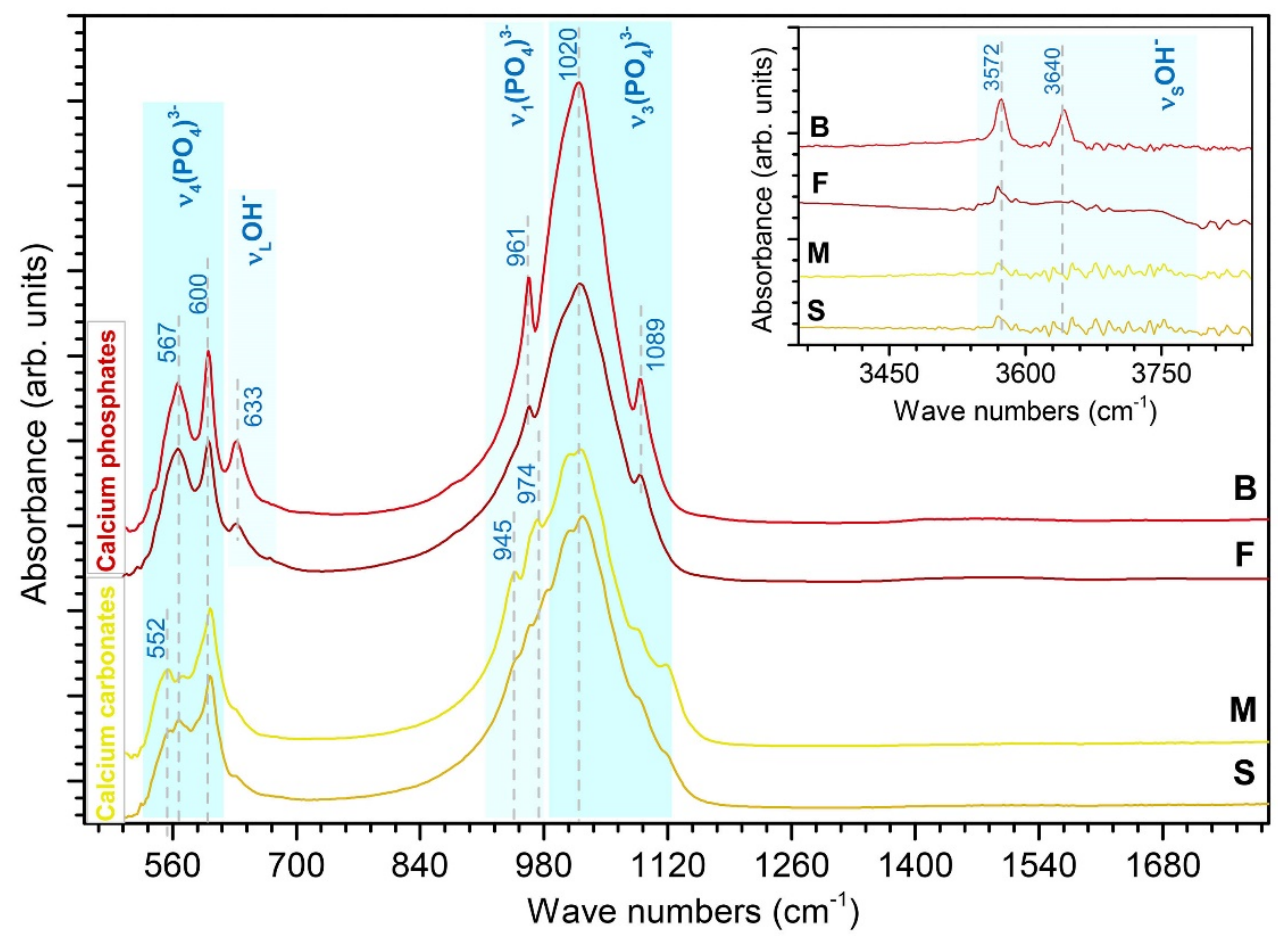

Figure 3. Representative IR spectra of bioceramic products derived from marble $(\mathrm{M})$, seashell $(\mathrm{S})$, bovine bone $(B)$ and fish bone $(F)$ precursors by chemical synthesis/calcination and sintering at $1200^{\circ} \mathrm{C}$.

\section{Compressive strength}

The mechanical performance of the developed products was evaluated by stress-strain curve measurements (Figure 4 - left) and compressive strength assays (Figure 4 - right). For all analysed samples, a fragile mechanical behaviour without any plastic deformations was depicted, typical for ceramic materials and accentuated in the case of calcium phosphates-derived ones.

Taking as a reference the corresponding compressive strength values for human bone, as host tissue in view of implantation $(120 \div 180 \mathrm{MPa}$ for the cortical bone type and $4 \div 12 \mathrm{MPa}$ for the cancellous one) [51], the obtained 
results resembles suitable outcomes. Moreover, the highest compressive strength values recorded for products derived from calcium phosphates sources are directly related to their phase composition - HA as single component (Figure 2), known for its increased mechanical resistance - and less influenced by their micro-porous character, as exposed by SEM micrographs (Figure 1). In contrast, as previously reported, marble and seashells lead to biphasic compositions even after the synthesis process, which is further converted through thermal treatment into the biphasic HA/ $\beta-\mathrm{TCP}[36,37]$. The degree of $\beta$-TCP component is considerable for both types of products and is well known for both its high biodegradability and poor mechanical features [28].

Regardless of the compactness/porous level of the products, as exposed in Figure 1, the obtained results are justified due to the modulated composition of the samples, as function of high temperature processing.
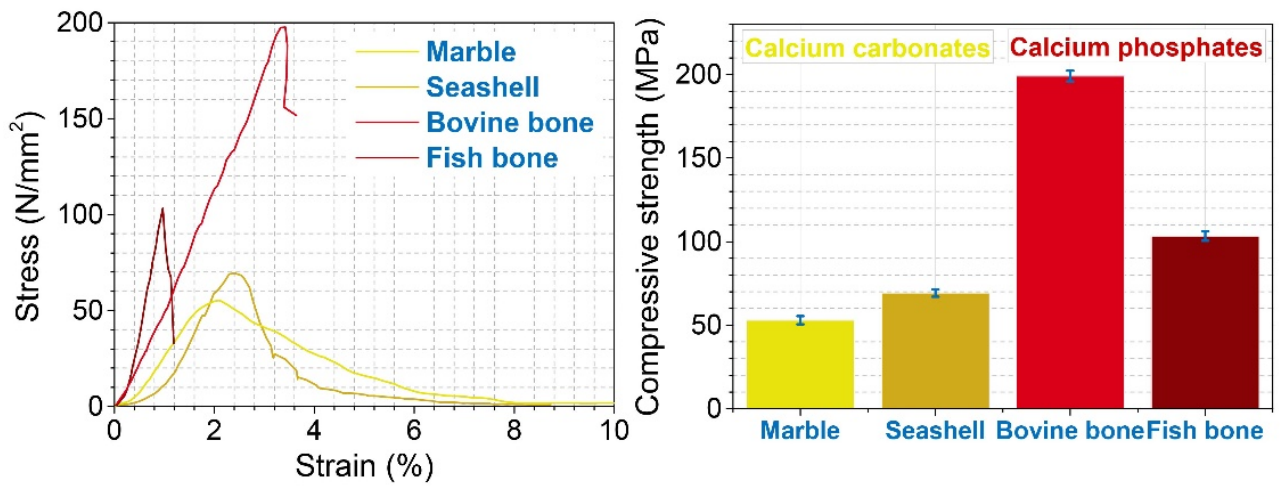

Figure 4. Comparative stress-strain curves (left) and compressive strength (right) for bioceramic products derived from marble, seashell, bovine bone and fish bone precursors by chemical synthesis/calcination and sintering at $1200^{\circ} \mathrm{C}$.

\section{CONCLUSIONS}

This research provided an insightful investigation of four possible natural precursors - marble, seashells, bovine bone and fish bone - as raw resources for biogenic calcium phosphates synthesis. Accordingly, the two already developed technologies, completely parameterized and reproducible led to the fabrication of two types of ceramic products. The morphocompositional, structural and mechanical investigations carried out in this regard, revealed that samples derived from marble and seashells consist of a biphasic calcium phosphate with different degree of HA/ $\beta$-TCP ratio, while the bovine and fish bones promote the conservation of single HA counterpart, 
COMPARATIVE FRAMEWORK OF CALCIUM PHOSPHATES-BASED PRODUCTS DERIVED FROM

SUSTAINABLE MARINE AND TERRESTRIAL RESOURCES FOR BIOMEDICAL APPLICATIONS

without additional structural or compositional events. The sintering program also promoted the development of compact structures with accentuated porous character and mechanical resistance for products derived from the last two precursors.

Future perspectives are envisioned for the developed biogenic products in terms of optimal vascularization and osseointegration and prospect industrial fabrication based on further thoroughly examination.

\section{EXPERIMENTAL SECTION}

\section{Naturally-derived products preparation}

Experiments were performed on products prepared from calcium phosphates powders derived from four marine and terrestrial natural resources, two based on calcium carbonates (e.g. dolomitic marble and marine seashells) and the other two based on calcium phosphates (e.g. bovine bone and fish bone: carp bones (Cyprinus carpio)).

The initial bioceramic powders were synthesized through different conversion routes for each type of natural precursor. Mable and seashells followed an already established and reproducible indirect chemical precipitation route based on thermal dissociation of the calcium carbonate (air thermal treatment, $1300^{\circ} \mathrm{C}, 6 \mathrm{~h}$ ) and phosphoric acid treatment under stoichiometric conditions, as previously reported [28, 36, 37, 46]. For calcium phosphatesbased precursors, the procedure involved initially the removal of soft tissue and organic components through mechanical removal of meat/soft tissue and boiling (in distilled water). Then, bone pieces were calcined in an electrical furnace at $500^{\circ} \mathrm{C}$ to $48 \mathrm{~h}$ followed by several heat treatments in air atmosphere for extended periods of time, as previously reported [21].

The compact products were obtained by isostatic pressing the synthesized bioceramic powders (grinded in advance with an agate mortar and pestle) in cylindrical moulds ( $\Phi 10 \mathrm{~mm}$ ) at $2.5 \mathrm{MPa}$, for $3 \mathrm{~min}$, using a Bernardo WK $50 \mathrm{FH}$ PRO work press. The pressed samples were further subjected to a conventional air sintering program in electrical furnace, at $1200^{\circ} \mathrm{C}$, for $8 \mathrm{~h}$. Samples were slowly cooled in the furnace, and deposited in sterile Petri dishes.

\section{Experimental assessment}

The morpho-compositional features of the sintered samples were studied with a scanning electron microscope (Philips XL 30 ESEM TMP) coupled with a microanalysis auxiliary system (EDAX Sapphire UTW). EDS 
analyses were performed on three randomly chosen areas of each sample. The $\mathrm{Ca} / \mathrm{P}$ atomic ratio was determined from the EDS results and will be expressed as a mean of the three independent results \pm standard deviation.

The crystalline structure of the sintered samples was investigated using a Bruker D8 Advance X-ray diffractometer, with Cu Ka $(\lambda=1.5418 \AA)$ radiation. The $X R D$ analyses were performed in the $2 \theta=9 \div 70^{\circ}$ angular range, with a step size of $0.02^{\circ}$ and $2 \mathrm{~s}$ acquisition time/ step.

The bonding architecture and functional groups presence in the sintered samples was evaluated after sintering by Fourier Transform Infrared spectroscopy (FTIR) in attenuated total reflectance (ATR) mode using a PerkinElmer Spectrum BX II spectrometer equipped with a Pike-MIRacle ATR head - diamond crystal. The FTIR-ATR spectra were recorded in the $500 \div 4000 \mathrm{~cm}^{-1}$ range at a spectral resolution of $4 \mathrm{~cm}^{-1}$. A total of 32 scans/ experiment were performed.

Compressive testing was performed using a Walter + Bai LFV 300 universal testing machine, on smooth cylindrical samples $(n=5 /$ sample precursor type), with a final diameter of $9.0 \pm 0.3 \mathrm{~mm}$ and a final height of $9.0 \pm 1.4 \mathrm{~mm}$. The machine cross head speed was set to $1 \mathrm{~mm} / \mathrm{min}$ with data acquisition time at $0.05 \mathrm{~s}$.

\section{REFERENCES}

1. J.N.F. Holanda; Springer International Publishing; 2017; 1-18.

2. A. Popa, G. Stan, M. Husanu, I. Mercioniu, L. Santos, H. Fernandes and J. Ferreira; Int. J. Nanomedicine; 2017; 12; 683.

3. B.W. Stuart, J.W. Murray and D.M. Grant; Scientific reports; 2018; 8;

4. I. Antoniac, D. Popescu, A. Zapciu, A. Antoniac, F. Miculescu and H. Moldovan; Materials; 2019; 12; 719.

5. H.R. Fernandes, A. Gaddam, A. Rebelo, D. Brazete, G.E. Stan and J.M. Ferreira; Materials; 2018; 11; 2530.

6. M. Ionita, L.E. Crica, S.I. Voicu, A.M. Pandele and H. lovu; Polym Adv Technol; 2016; 27; 350-357.

7. F. Baino and M. Ferraris; Int. J. Appl. Ceram. Technol.; 2017; 14; 507-520.

8. F. Miculescu, M. Miculescu, L. Ciocan, A. Ernuteanu, I. Antoniac, I. Pencea and E. Matei; Dig. J. Nanomater. Biostructures (DJNB); 2011; 6;

9. N. Stevulova, A. Estokova, J. Cigasova, I. Schwarzova, F. Kacik and A. Geffert; J. Therm. Anal. Calorim.; 2017; 128; 1649-1660.

10. T. Tite, A.-C. Popa, L. Balescu, I. Bogdan, I. Pasuk, J. Ferreira and G. Stan; Materials; 2018; 11; 2081. 
COMPARATIVE FRAMEWORK OF CALCIUM PHOSPHATES-BASED PRODUCTS DERIVED FROM SUSTAINABLE MARINE AND TERRESTRIAL RESOURCES FOR BIOMEDICAL APPLICATIONS

11. Ö. Özmen, R. Sârbu, A. S. Săseanu and C. Toader; Amfiteatru Econ.; 2017; 19; 1064-1064.

12. M. Ebrahimi, M. G. Botelho and S. V. Dorozhkin; Mater. Sci. Eng. C; 2017; 71; 1293-1312.

13. Q. Zhang, W. Wu, C. Qian, W. Xiao, H. Zhu, J. Guo, Z. Meng, J. Zhu, Z. Ge and W. Cui; Mater. Sci. Eng. C; 2019; 103; 109858.

14. M. Castilho, C. Moseke, A. Ewald, U. Gbureck, J. Groll, I. Pires, J. Teßmar and E. Vorndran; Biofabrication; 2014; 6; 015006.

15. M. Garcés Villalá, J. Calvo Guirado, D. Granados, S. Limandri and V. Galván Josa; X-Ray Spectrom.; 2017; 46; 237-241.

16. C. Danoux, D. Pereira, N. Döbelin, C. Stähli, J. Barralet, C. van Blitterswijk and P. Habibovic; Adv. Healthc. Mater.; 2016; 5; 1775-1785.

17. G. Stan, A. Popa and D. Bojin; Dig. J. Nanomater. Biostructures (DJNB); 2010; 5;

18. G. Armencea, C. Berce, M. Todea, A. Vulpoi, D. Leordean, S. Bran, C. Dinu, M. Lazar, O. Lucaciu and L. Crisan; Studia UBB, Chemia; 2019; 64;

19. M. Mucalo; Hydroxyapatite (HAp) for biomedical applications; 2015; 307.

20. F. Barrère, C.A. van Blitterswijk and K. de Groot; Int. J. Nanomedicine; 2006; 1; 317.

21. A. Maidaniuc, F. Miculescu, S. I. Voicu, C. Andronescu, M. Miculescu, E. Matei, A. C. Mocanu, I. Pencea, I. Csaki and T. Machedon-Pisu; Appl. Surf. Sci.; 2018; 438; $158-166$.

22. C. Sarosi, A.R. Biris, A. Antoniac, S. Boboia, C. Alb, I. Antoniac and M. Moldovan; J Adhes Sci Technol; 2016; 30; 1779-1794.

23. S. Lala, M. Ghosh, P. Das, D. Das, T. Kar and S. Pradhan; Mater. Chem. Phys.; 2016; 170; 319-329.

24. L. Galea, D. Alexeev, M. Bohner, N. Doebelin, A.R. Studart, C.G. Aneziris and T. Graule; Biomaterials; 2015; 67; 93-103.

25. A. Vladescu, M. Badea, S.C. Padmanabhan, G. Paraschiv, L. Floroian, L. Gaman, M.A. Morris, J.-L. Marty and C.M. Cotrut; Elsevier; 2019; 409-431.

26. L. Bizo, K. Sabo, R. Barabas, G. Katona, L. Barbu-Tudoran and A. Berar; Studia UBB , Chemia; 2020; 65;

27. A. Maidaniuc, F. Miculescu, R.C. Ciocoiu, T.M. Butte, I. Pasuk, G.E. Stan, S.I. Voicu and L.T. Ciocan; Ceram. Int; 2020; 46; 10159-10171.

28. A.-C. Mocanu, M. Miculescu, T. Machedon-Pisu, A. Maidaniuc, R.C. Ciocoiu, M. Ioniță, I. Pasuk, G.E. Stan and F. Miculescu; Appl. Surf. Sci.; 2019; 489; 226238.

29. A.-I. Bita, G. Stan, M. Niculescu, I. Ciuca, E. Vasile and I. Antoniac; J Adhes Sci Technol.; 2016; 30; 1968-1983.

30. A. Moldoveanu, O.-M. Ferche, F. Moldoveanu, R.G. Lupu, D. Cinteză, D.C. Irimia and C. Toader; IEEE Access; 2019; 7; 8151-8171.

31. M. Montazerolghaem, M.K. Ott, H. Engqvist, H. Melhus and A. Rasmusson; Mater. Sci. Eng. C; 2015; 52; 212-218.

32. G. Cama, S. Nkhwa, B. Gharibi, A. Lagazzo, R. Cabella, C. Carbone, P. Dubruel, H. Haugen, L. Di Silvio and S. Deb; Mater. Sci. Eng. C; 2017; 78; 485-494.

33. M. O'Halloran; Journal of Research\&Practice in Dentistry; 2014; 2014; 1-19. 
A.-C. MOCANU, M. MICULESCU, R.-C. CIOCOIU, T.-M. BUTTE, A.-I. BITฺ̆,

C.-G. MILEA, A. ANTONIAC, M. VASILESCU, O. TRANTE, C. POP, L.-T. CIOCAN

34. M.K. Herliansyah, C. Muzafar and A.E. Tontowi; Ind. Eng. Manag. Syst.; 2012; 1135-1145.

35. F. Miculescu, A. Maidaniuc, S. Voicu, M. Miculescu, A. Berbecaru, L. Ciocan, A. Purcaru, A. Semenescu and O. Preda; J. Optoelectron. Adv. M.; 2015; 17; 1361-1366.

36. F. Miculescu, A.C. Mocanu, G.E. Stan, M. Miculescu, A. Maidaniuc, A. Cîmpean, V. Mitran, S.I. Voicu, T. Machedon-Pisu and L.T. Ciocan; Appl. Surf. Sci.; 2018; 438; 147-157.

37. A.-C. Mocanu, G.E. Stan, A. Maidaniuc, M. Miculescu, I.V. Antoniac, R.-C. Ciocoiu, Ș.I. Voicu, V. Mitran, A. Cîmpean and F. Miculescu; Materials; 2019; $12 ; 381$.

38. F. Miculescu, G. Stan, L. Ciocan, M. Miculescu, A. Berbecaru and I. Antoniac; Dig. J. Nanomater. Biostructures (DJNB); 2012; 7;

39. F. Heidari, M. Razavi, M. Ghaedi, M. Forooghi, M. Tahriri and L. Tayebi; J. Alloys Compd.; 2017; 693; 1150-1156.

40. A. Maidaniuc, M. Miculescu, S. Voicu, L. Ciocan, M. Niculescu, M. Corobea, M. Rada and F. Miculescu; J Adhes Sci Technol,; 2016; 30; 1829-1841.

41. M. Moldovan, D. Prodan, C. Sarosi, R. Carpa, C. Socaci, M.-C. Rosu and S. Pruneanu; Mater. Chem. Phys.; 2018; 217; 48-53.

42. F. Miculescu, A.-C. Mocanu, C.A. Dascălu, A. Maidaniuc, D. Batalu, A. Berbecaru, S.I. Voicu, M. Miculescu, V.K. Thakur and L.T. Ciocan; Vacuum; 2017; 146; 614-622.

43. C.M. Cotrut, A. Vladescu, M. Dinu and D.M. Vranceanu; Ceram. Int; 2018; 44; 669-677.

44. B. Cecen, L.D. Kozaci, M. Yuksel, O. Ustun, B.U. Ergur and H. Havitcioglu; Mater. Sci. Eng. C; 2016; 69; 437-446.

45. M. Vranceanu, I. Antoniac, F. Miculescu and R. Saban; J. Optoelectron. Adv. Mater.; 2012; 14; 671-677.

46. V. Mitran, R. Ion, F. Miculescu, M.G. Necula, A.-C. Mocanu, G.E. Stan, I.V. Antoniac and A. Cimpean; Materials; 2018; 11; 1097.

47. F. Miculescu, L. Ciocan, M. Miculescu and A. Ernuteanu; Dig. J. Nanomater. Biostructures (DJNB); 2011; 6; 225-233.

48. M. Markovic, B.O. Fowler and M.S. Tung; J Res Natl Inst Stand Technol; 2004; 109; 553.

49. A. Rapacz-Kmita, C. Paluszkiewicz, A. Ślósarczyk and Z. Paszkiewicz; J. Mol. Struct.; 2005; 744; 653-656.

50. M. Lombardi, P. Palmero, K. Haberko, W. Pyda and L. Montanaro; J. Eur. Ceram. Soc.; 2011; 31; 2513-2518.

51. J.-Y. Rho, L. Kuhn-Spearing and P. Zioupos; Med Eng Phys; 1998; 20; 92-102. 